\title{
Retrospective review of patients with atrial fibrillation: does pulmonary vein isolation make a difference?
}

\author{
Ronald B Williams*, Sahadev T Reddy, Mark Doyle, June Yamrozik, Vikas K Rathi, Robert W Biederman \\ From 15th Annual SCMR Scientific Sessions \\ Orlando, FL, USA. 2-5 February 2012
}

\section{Summary}

The success rate in patients with atrial fibrillation that were treated with pulmonary vein ablation is suboptimal. In retrospective review, those PVI patients that sustained normal sinus rhythm showed improvement in LV function and reverse remodeling of mitral apparatus when compared to those that had no response.

\section{Background}

It has been documented in the literature that patients with chronic or recurrent atrial fibrillation (AF) undergo left atrial remodeling as well as mitral annulus changes presumably related to volume overload within the atrium. We wish to show that cardiac MRI (CMR) imaging can be utilized for pre and post PVI for AF evaluation of atrial and LV annular remodeling.

\section{Methods}

Ninety four (94) patients, with AF, (19 females; $59 \pm 9.9$ years; 57 males, $49 \pm 9.7$ years with sustained normal sinus rhythm (NSR) and eighteen (18; 4 females \pm 6 years; 14 males, $56 \pm 9$ years) post-PVI recurrent or failures), underwent CMR using standard, SSFP imaging, (GE Excite HD, 1.5, Milwaukee, WI). Routine VLA, HLA, LVOT views were obtained as well as MRA for $3 \mathrm{D}$ viewing of pulm.

\section{Results}

All 94 patients were reviewed, 76 (81\%) of those with successful PVI resulting in sustained NSR, showed significant improvement in their mitral apparati and MR severity. Those AF patients that didn't respond to PVI, showed no significant changes in either MR reduction or geometric remodeling (Table 1 and 2).

\section{Conclusions}

Patients treated with PVI for AF demonstrate significant improvement in LV function and secondary improvement in LV/atrial reverse remodeling with subsequent improvement in MR only in responders (NSR). Patients who failed PVI show no significant improvement in degree of MR or any LV/atrial metrics.

\section{Funding}

Internal.

Published: 1 February 2012

Table 1 NSR Patients Pre/Post

\begin{tabular}{cccc}
\hline $\mathrm{n}=76$ & & & \\
\hline CMR Cardiac Parameter & Pre PVI & Post PVI & P Value \\
\hline LA Volume (ml) & $230 \pm 70$ & $199 \pm 66$ & 0.01 \\
LVEF\% & $57 \pm 10$ & $60 \pm 6$ & 0.01 \\
MR Severity (Mean) & $0.78 \pm 0.8$ & $0.51 \pm 0.9$ & 0.01 \\
Mitral Annulus Diameter (mm) & $34.5 \pm 3.9$ & $32.6 \pm 3.9$ & $<0.001$ \\
Mitral Tenting Area (mm2) & $169.7 \pm 55.9$ & $138.9 \pm 40.6$ & $<0.001$ \\
Mitral Tenting Height (mm) & $8.0 \pm 2.0$ & $7.2 \pm 1.8$ & $<0.001$ \\
Mitral Tenting Angle & $131.2 \pm 11.6$ & $130.8 \pm 9.7$ & NS \\
\hline
\end{tabular}

Allegheny General Hospital, Pittsburgh, USA

(c) 2012 Williams et al; licensee BioMed Central Ltd. This is an open access article distributed under the terms of the Creative Commons B. Wed Central Attribution License (http://creativecommons.org/licenses/by/2.0), which permits unrestricted use, distribution, and reproduction in any medium, provided the original work is properly cited. 
Table 2 Patients that did not Respond to PVI

\begin{tabular}{cccc}
\hline \multicolumn{1}{c}{$\mathrm{n}=18$} & & & \\
\hline CMR Cardiac Parameter & Pre PVI & Post PVI & P Value \\
\hline LA Volume (ml) & $207 \pm 55$ & $183 \pm 85$ & 0.05 \\
LVEF\% & $59.3 \pm 10$ & $60.9 \pm 8.6$ & $\mathrm{NS}$ \\
MR Severity (mean) & $1.1 \pm 0.8$ & $0.7 \pm 0.9$ & $\mathrm{NS}$ \\
Mitral Annulus Diameter (mm2) & $33.1 \pm 4$ & $32.9 \pm 3.7$ & $\mathrm{NS}$ \\
Mitral Tenting Area (mm2) & $154 \pm 41.8$ & $143.8 \pm 45.4$ & $\mathrm{NS}$ \\
Mitral Tenting Height (mm & $6.9 \pm 1.9$ & $7.0 \pm 1.8$ & $\mathrm{NS}$ \\
Mitral Tenting Angle (degrees) & $131.2 \pm 11.6$ & $130.8 \pm 9.7$ & $\mathrm{NS}$ \\
\hline
\end{tabular}

doi:10.1186/1532-429X-14-S1-T3

Cite this article as: Williams et al:: Retrospective review of patients with atrial fibrillation: does pulmonary vein isolation make a difference?

Journal of Cardiovascular Magnetic Resonance 2012 14(Suppl 1):T3.

Submit your next manuscript to BioMed Central and take full advantage of:

- Convenient online submission

- Thorough peer review

- No space constraints or color figure charges

- Immediate publication on acceptance

- Inclusion in PubMed, CAS, Scopus and Google Scholar

- Research which is freely available for redistribution

Submit your manuscript at www.biomedcentral.com/submit
C Biomed Central 